\title{
MAGNETIC SUSCEPTIBILITY DISACCOMMODATION AND MÖSSBAUER EFFECT IN MICROCRYSTALLINE Fe-Si RIBBONS
}

\author{
W.H. CIURZYŃSKA \\ Institute of Physics, Technical University of Częstochowa \\ Al. Armii Krajowej 19, 42-200 Częstochowa, Poland
}

(Received November 30, 1999)

In memory of Professor Jerzy Wojciech Moroń

The magnetic susceptibility disaccommodation of the microcrystalline $\mathrm{Fe}-x \mathrm{Si}(x=3,5,6.5$, and $7.2 \mathrm{wt} \%)$ ribbons in the as-quenched state and after annealing at $1370 \mathrm{~K}$ for $1 \mathrm{~h}$ was investigated in the temperature range from 220 to $410 \mathrm{~K}$. Simultaneously, the microstructure of those samples was studied using the Mössbauer spectroscopy. It is found that the isochronal disaccommodation curves may be decomposed into five elementary processes. Taking into account the results obtained from the Mössbauer spectra analysis, the relaxational process with activation energy equal to $0.84 \mathrm{eV}$ may be considered as the Snoek relaxation. However, the relaxational processes of higher activation energy seem to be connected with jumps of $\mathrm{C}$ atoms in the vicinity of Fe atoms surrounded by 1, 2, 3, and 4 silicon atoms.

PACS numbers: $75.60 . \mathrm{Lr}, 76.80 .+\mathrm{y}$

\section{Introduction}

Many experimental investigations have been devoted to the disaccommodation phenomenon in metals with $A 2$ structure. It was found that the magnetic susceptibility disaccommodation (MSD) in these metals is connected with directional ordering of the interstitial solute atoms (i), e.g. C and $\mathrm{N}$ [1]. The relaxation spectrum observed in $\alpha$-Fe containing $\mathrm{C}$ or $\mathrm{N}$ (e.g. [1-3]) appears in the temperature range $245-259 \mathrm{~K}$ due to the jumps of interstitials in the vicinity of $\mathrm{Fe}$ atoms (the Snoek relaxation). From investigations carried out for $\alpha-\mathrm{Fe}-3 \mathrm{wt} \% \mathrm{Si}$ alloys in the form of sheets and monocrystals it was found [4-9] that the magnetic susceptibility disaccommodation band is considerably broader than in $\mathrm{Fe}-\mathrm{C}(\mathrm{N})$ and consists of two parts:

1. the low temperature part originating from the Snoek relaxation occurring also in $\alpha-\mathrm{Fe}-\mathrm{C}(\mathrm{N})$ alloys, 
2. the part at higher temperature originating from $\mathrm{C}$ and/or $\mathrm{N}$ atoms jumping near silicon atoms.

In the case of $\mathrm{Fe}-\mathrm{Si}$ alloys containing more than $3 \mathrm{wt} \% \mathrm{Si}$, the observed relaxation spectrum is more complex [10-18]. However, the origin of that phenomenon has not been explained until now.

The aim of this paper is to find the origin of the magnetic susceptibility disaccommodation in microcrystalline $\mathrm{Fe}-x \mathrm{Si}(x=3,5,6.5$, and $7.2 \mathrm{wt} \%)$ ribbons in the as-quenched state and after annealing at $1370 \mathrm{~K}$ for $1 \mathrm{~h}$. In order to explain the dependence of the MSD intensity on silicon content, the microstructure of the mentioned ribbons was investigated using the Mössbauer spectroscopy.

\section{Samples and experimental procedure}

Microcrystalline $\mathrm{Fe}-x \mathrm{Si}(x=3,5,6.5$, and $7.2 \mathrm{wt} \%)$ ribbons were made by rapid quenching from the melt using the single roller method. Their thickness and width were $20 \mu \mathrm{m}$ and $10 \mathrm{~mm}$, respectively. The composition of iron used for the preparation of $\mathrm{Fe}-\mathrm{Si}$ samples is presented in Table I. Moreover, the purity of silicon was greater than $99.999 \%$.

\section{TABLE I}

The impurity content in iron (wt\%) used for the preparation of $\mathrm{Fe}-\mathrm{Si}$ ribbons.

\begin{tabular}{c|c|c|c|c|c|c}
\hline \hline $\mathrm{C}$ & $\mathrm{S}$ & $\mathrm{P}$ & $\mathrm{Si}$ & $\mathrm{Mn}$ & $\mathrm{Cu}$ & $\mathrm{O}$ \\
\hline$<0.005$ & $<0.005$ & $<0.0012$ & $<0.018$ & $<0.0016$ & $<0.002$ & $<0.097$
\end{tabular}

The measurements of the susceptibility $(\chi)$ of the $\mathrm{Fe}-x \mathrm{Si}(x=3,5,6.5$, and $7.2 \mathrm{wt} \%$ ) ribbons in the as-quenched state and after annealing in vacuum at $1370 \mathrm{~K}$ for $1 \mathrm{~h}$ (pressure $p=0.5 \mathrm{~Pa}$, cooling rate after heating from $1370 \mathrm{~K}$ to room temperature $k=360 \mathrm{~K} / \mathrm{min}$ ) were performed by means of a Maxwell-Wien bridge. The magnetizing field amplitude and frequency were equal to $0.16 \mathrm{~A} / \mathrm{m}$ and $3.03 \mathrm{kHz}$, respectively. From the measurements of the magnetic susceptibility, the isochronal disaccommodation $\Delta(1 / \chi)=1 / \chi_{2}-1 / \chi_{1}$ versus temperature $(T)$ was constructed: $1 / \chi_{2}$ and $1 / \chi_{1}$ are reciprocal magnetic susceptibilities at times $t_{1}=25 \mathrm{~s}$ and $t_{2}=295 \mathrm{~s}$ after demagnetization of the samples.

The $\Delta(1 / \chi)=f(T)$ curves were decomposed into elementary processes, each of them being described by a single time constant. The theoretical curves were calculated using the formula [19]:

$$
\Delta\left(\frac{1}{\chi}\right)=\frac{1}{\chi_{2}}-\frac{1}{\chi_{1}}=\sum_{i=1}^{n} A_{i}\left[\exp \left(-\frac{t_{1}}{\theta_{i}}\right)-\exp \left(-\frac{t_{2}}{\theta_{i}}\right)\right]
$$

with

$$
\theta_{i}=\theta_{0 i} \exp \left(\frac{Q_{i}}{k T}\right)
$$

where $Q_{i}$ is the activation energy, $\theta_{0 i}$ - pre-exponential factor and $A_{i}$ - relaxation intensity of the $i$-th process $[2,3,19]$. 
The microstructure of $\mathrm{Fe}-x \mathrm{Si}(x=3,5,6.5$, and $7.2 \mathrm{wt} \%)$ samples was examined using the Mössbauer spectroscopy (MS). The transmission Mössbauer spectra for the samples with the thickness of about $20 \mu \mathrm{m}$ were measured at room temperature by means of a conventional constant acceleration spectrometer with ${ }^{57} \mathrm{Co}$ in a $\mathrm{Rh}$ source of $25 \mathrm{mCi}$ activity. The Mössbauer spectra were analysed with a least-squares method by superimposing sets of the Zeeman sextets. The ratios of the relative line intensities in the Zeeman sextets were $A_{1,6}: A_{2,5}: A_{3,4}=$ $3: A_{2,5}: 1$, where $A_{2,5}$ was fitted and assumed the same for all subspectra in each Mössbauer spectrum. From the analysis of the Mössbauer spectra, the magnetization distribution, average hyperfine field at the ${ }^{57} \mathrm{Fe}$ nuclei and order degree were also determined.

The long range order parameters ( $S_{1}$ for $\mathrm{DO}_{3}$ and $S_{2}$ for $B 2$ structures) were calculated from the equations

$$
S_{1}=2\left(P_{A}^{\beta}-P_{A}^{\alpha}\right)
$$

and

$$
S_{2}=2\left(P_{A}^{\gamma}-c_{A}\right)
$$

where $P_{A}^{\beta}, P_{A}^{\alpha}$, and $P_{A}^{\gamma}$ are probabilities for iron atoms to occupy corresponding sites in bcc lattice ( $\alpha, \beta$ are sites of $\mathrm{Fe}$ and $\mathrm{Si}$ atoms in the body and $\gamma-$ in the corner of the cell) and $c_{A}$ is the iron content [20].

However, the short range order parameter $\alpha_{1}$ (the Cowley-Warren parameter) for the first coordination zone was determined from

$$
\alpha_{1}=1-\frac{P_{B}}{1-c_{B}}
$$

where $P_{B}$ are probabilities of the occurrence of Si atoms in the first coordination zone of the iron atom and $c_{B}$ is the silicon content [21].

All studies were performed for the samples in the as-quenched state and after annealing at $1370 \mathrm{~K}$ for $1 \mathrm{~h}$.

Additionally, the observation of the domain structure in the individual grains of annealed specimens was carried out by means of the Bitter method.

\section{Results}

In Fig. 1 the dependence of the magnetic susceptibility (measured at $t_{1}=25 \mathrm{~s}$ after demagnetization) on the temperature, obtained for $\mathrm{Fe}-x \mathrm{Si}(x=3,5,6.5$, and $7.2 \mathrm{wt} \%$ ) samples after annealing at $1370 \mathrm{~K}$ for $1 \mathrm{~h}$, is presented. The inset in Fig. 1 shows, as an example, the magnetic susceptibility of $\mathrm{Fe}-7.2 \% \mathrm{Si}$ ribbon in the as-quenched state and after annealing at $1370 \mathrm{~K}$ for $1 \mathrm{~h}$. As can be seen from this inset, the magnetic susceptibility of $\mathrm{Fe}-7.2 \% \mathrm{Si}$ sample in the as-quenched state only slightly depends on the temperature. The $\mathrm{Fe}-x \mathrm{Si}(x=3,5$ and 6.5 wt\%) samples in the as-quenched state exhibit the similar behaviour. Annealing of the $\mathrm{Fe}-x \mathrm{Si}(x=3,5,6.5$, and $7.2 \mathrm{wt} \%)$ samples at $1370 \mathrm{~K}$ for $1 \mathrm{~h}$ leads to the increase in the magnetic susceptibility in comparison with $\chi$ of the samples in the as-quenched state; e.g. for $\mathrm{Fe}-7.2 \%$ Si sample $\chi$ at room temperature increases about 4 times (from 400 to 1780 ). The values of the magnetic susceptibility, obtained for the samples in the as-quenched state and after annealing at $1370 \mathrm{~K}$ for 

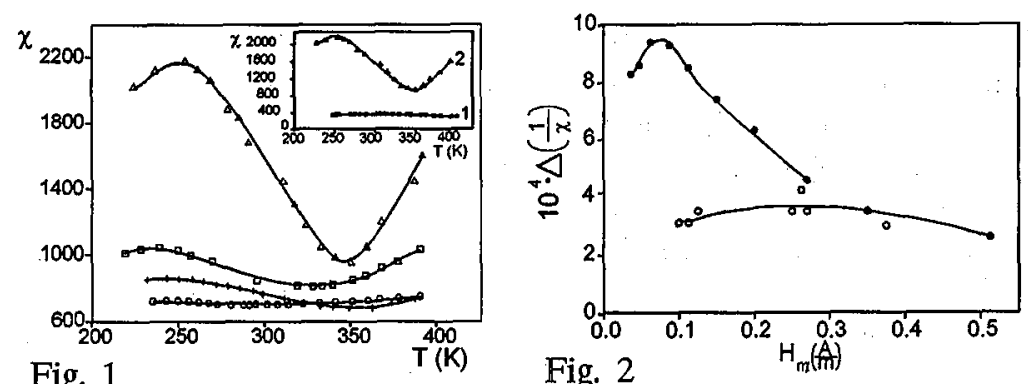

Fig. 1

Fig. 2

Fig. 1. The dependence $\chi=f(T)$ for the Fe- $x$ Si microcrystalline ribbons after annealing at $1370 \mathrm{~K}$ for $1 \mathrm{~h}: x=3(0), x=5(+), x=6.5(\square)$ and $x=7.2 \mathrm{wt} \%(\triangle)$. The inset: the relationship $\chi=f(T)$ obtained for the Fe-7.2\%Si ribbons in as-quenched state (curve 1) and after annealing at $1370 \mathrm{~K}$ for $1 \mathrm{~h}$ (curve 2).

Fig. 2. The dependence $\Delta(1 / \chi)=\dot{f}\left(H_{\mathrm{m}}\right)$ for the Fe-5\%Si ribbons in the as-quenched state $(0)$ and after annealing at $1370 \mathrm{~K}$ for $1 \mathrm{~h}(\bullet)$.

\section{TABLE II}

The values of magnetic susceptibility (measured at room temperature, $t_{1}=25 \mathrm{~s}$ after demagnetization) for the microcrystalline $\mathrm{Fe}-x \mathrm{Si}(x=3,5,6.5$, and $7.2 \mathrm{wt} \%)$ samples in the as-quenched state (As-q) and after annealing at $1370 \mathrm{~K}$ for $1 \mathrm{~h}$ (Ann).

\begin{tabular}{c|c|c|c|c|c|c|c|c}
\hline \hline & \multicolumn{2}{|c|}{$\mathrm{Fe}-3 \% \mathrm{Si}$} & \multicolumn{2}{c|}{ Fe-5\%Si } & \multicolumn{2}{c|}{ Fe-6.5\%Si } & \multicolumn{2}{c}{ Fe-7.2\%Si } \\
\cline { 2 - 9 } & As-q & Ann & As-q & Ann & As-q & Ann & As-q & Ann \\
\hline$\chi$ & 60 & 700 & 190 & 780 & 280 & 850 & 400 & 1780
\end{tabular}

$1 \mathrm{~h}$, measured at room temperature at $t_{1}=25 \mathrm{~s}$ after demagnetization, are listed in Table II.

The shape of $\chi=f(T)$ curves of annealed samples (Fig. 1) depends on the silicon concentration: the higher content of $\mathrm{Si}$ involves the greater changes in $\chi=f(T)$ curves.

In Fig. 2 the isochronal disaccommodation $\Delta(1 / \chi)$ versus the amplitude of the magnetizing field $\left(H_{\mathrm{m}}\right)$, obtained for $\mathrm{Fe}-5 \% \mathrm{Si}$ ribbons in the as-quenched state and after annealing at $1370 \mathrm{~K}$ for $1 \mathrm{~h}$, as an example, is presented. The disaccommodation intensity reaches a maximum at $H_{\mathrm{m}}=H_{\mathrm{s}}$ (stabilization field) and then monotonically decreases. As can be seen, for the annealed sample the disaccommodation intensity is higher and stabilization field is lower in comparison with the sample in the as-quenched state. Similar results were obtained for the $\mathrm{Fe}-x \mathrm{Si}(x=3,6.5$, and $7.2 \mathrm{wt} \%)$ samples.

In Fig. 3 the $\Delta(1 / \chi)=f(T)$ curves obtained for $\mathrm{Fe}-x \mathrm{Si}(x=3,5,6.5$, and $7.2 \mathrm{wt} \%)$ ribbons after annealing at $1370 \mathrm{~K}$ for $1 \mathrm{~h}$ are shown. As can be seen, the disaccommodation band occurs in the temperature region from 240 to $400 \mathrm{~K}$. The shape of the $\Delta(1 / \chi)=f(T)$ curves, obtained for different alloys depends on the concentration of $\mathrm{Si}$ atoms. For $\mathrm{Fe}-3 \mathrm{wt} \% \mathrm{Si}$ a high maximum occurs at $250 \mathrm{~K}$. 


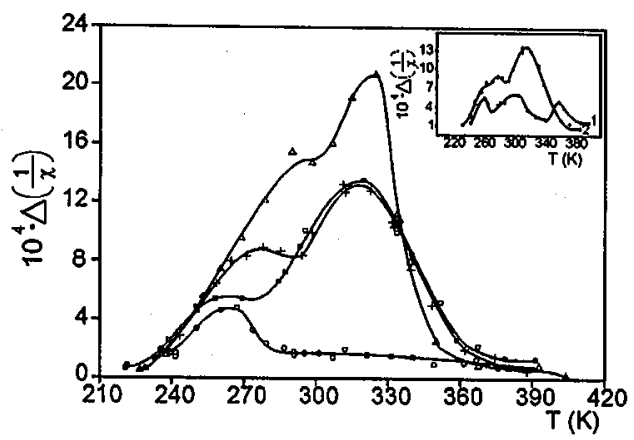

Fig. 3. The dependence $\Delta(1 / \chi)=f(T)$ obtained for Fe- $x$ Si microcrystalline ribbons after annealing at $1370 \mathrm{~K}$ for $1 \mathrm{~h}: x=3(0), x=5(+), x=6.5(\square)$ and $x=7.2 \mathrm{wt} \%$ $(\Delta)$. The inset: the relationship $\Delta(1 / \chi)=f(T)$ obtained for Fe-5\%Si in the as-quenched state (curve 1 ) and after annealing at $1370 \mathrm{~K}$ for $1 \mathrm{~h}$ (curve 2).

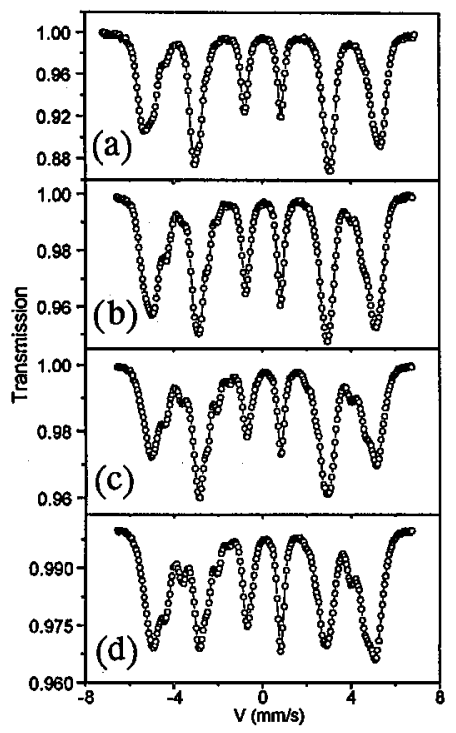

Fig. 4. Transmission Mössbauer spectra for $\mathrm{Fe}-x \mathrm{Si}(x=3,5,6.5$, and $7.2 \mathrm{wt} \%)$ after annealing at $1370 \mathrm{~K}$ for $1 \mathrm{~h} ; x=3$ (a), $x=5$ (b), $x=6.5$ (c) and $x=7.2 \mathrm{wt} \%$ (d).

For the Fe- $x \mathrm{Si}(x=5,6.5$, and $7.2 \mathrm{wt} \%)$ samples two distinct maxima in the isochronal disaccommodation curves are observed. The inset shows, as an example, $\Delta(1 / \chi)=f(T)$ curves obtained for the $\mathrm{Fe}-5 \% \mathrm{Si}$ samples in the as-quenched state and after annealing at $1370 \mathrm{~K}$ for $1 \mathrm{~h}$. As can be seen from the inset in this figure, the annealing of the samples causes the increase in the disaccommodation intensity.

Figure 4 shows the transmission Mössbauer spectra for the $\mathrm{Fe}-x \mathrm{Si}(x=3,5$, 6.5 , and $7.2 \mathrm{wt} \%$ ) samples after annealing at $1370 \mathrm{~K}$ for $1 \mathrm{~h}$. As can be seen from this figure, the observed Mössbauer spectra exhibit a complex structure. 


\section{Discussion}

The existence of migrational relaxation processes in microcrystalline $\mathrm{Fe}-\mathrm{Si}$ ribbons containing $\mathrm{C}$ and/or $\mathrm{N}$ in solid solution is proved by the occurrence of the phenomenon of magnetic susceptibility disaccommodation. The form of the $\Delta(1 / \chi)=f\left(H_{\mathrm{m}}\right)$ curve, showing a marked maximum at $H_{\mathrm{m}}=0.9 \mathrm{~A} / \mathrm{m}$ (Fig. 2), indicates that in the studied ribbons the disaccommodation process is primarily associated with migrational relaxations in the $180^{\circ}$ domain walls [14, 22]. Additionally, it was confirmed by the domain structure observation. It is seen (Fig. 5) that the domain patterns mainly consist of the domains separated by the $180^{\circ}$ Bloch walls.

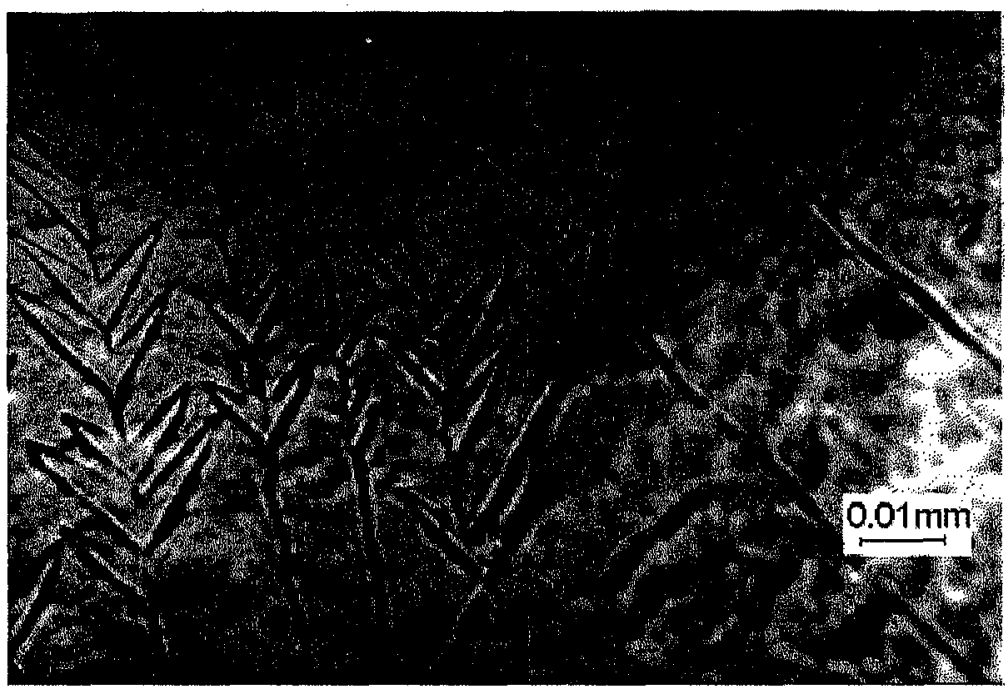

Fig. 5. The domain structure in the Fe-6.5\%Si microcrystalline samples annealed at $1370 \mathrm{~K}$ for $1 \mathrm{~h}$.

The band of the disaccommodation in investigated microcrystalline $\mathrm{Fe}-x \mathrm{Si}$ $(x=3,5,6.5$, and $7.2 \mathrm{wt} \%)$ alloys occurs in the temperature region from 240 to $400 \mathrm{~K}$, i.e. within a similar temperature range as in the case of $\mathrm{Fe}-\mathrm{Si}$ monocrystals and transformer sheets (e.g. [7]). The experimental $\Delta(1 / \chi)=f(T)$ curves were decomposed into five elementary processes of single time constants $\theta_{i}$. Figure 6 shows, as an example, the decomposition of the $\Delta(1 / \chi)=f(T)$ curve obtained for the $\mathrm{Fe}-5 \mathrm{wt} \% \mathrm{Si}$ ribbon annealed at $1370 \mathrm{~K}$ for $1 \mathrm{~h}$; the broken lines are the particular elementary processes and the solid line is the sum of them.

In Table III the activation energy $\left(Q_{i}\right)$ and intensity of elementary processes $\left(A_{i}\right)$ are listed. $\theta_{0 i}$ was imposed to be $3.2 \times 10^{-15} \mathrm{~s}$, according to $[2,3]$. The process with the activation energy equal to $0.84 \mathrm{eV}$ corresponds to the carbon Snoek relaxation in Fe [2, 3]. Taking into account the contribution of elementary processes (I, II, III, IV, and V) to the MSD phenomenon, one can see (Fig. 7) that the $A_{\mathrm{I}} / \sum A_{i}$ and $A_{\mathrm{II}} / \sum A_{i}$ ratios decrease and $A_{\mathrm{III}} / \sum A_{i}, A_{\mathrm{IV}} / \sum A_{i}$ and $A_{\mathrm{V}} / \sum A_{i}$ (where $i=1,2,3,4,5$ ) increase with $\mathrm{Si}$ content faster than linearly. 


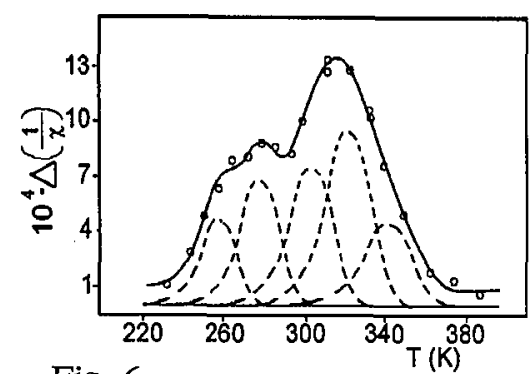

Fig. 6

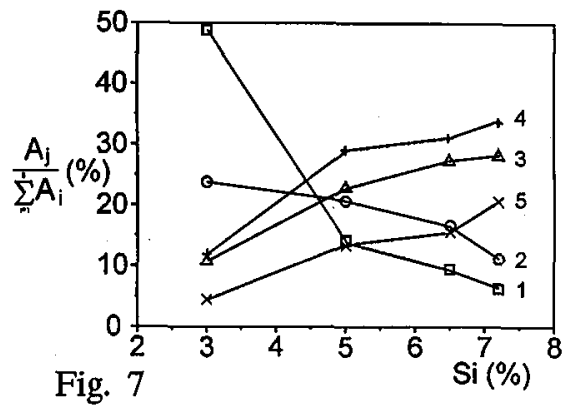

Fig. 6. Results of the $\Delta(1 / \chi)=f(T)$ curve analysis obtained for the Fe-5\%Si ribbons after annealing at $1370 \mathrm{~K}$ for $1 \mathrm{~h}$ : (0) experimental data, (- -) theoretical curves of elementary processes; (-) sum of theoretical curves.

Fig. 7. The dependence $A_{j} /\left(\sum_{i=1}^{5} A_{i}\right)$ versus Si concentration for elementary processes I-V (curves 1-5, respectively).

\section{TABLE III}

Activation energies $(Q[\mathrm{eV}])$ and intensities $\left(A\left[\times 10^{-4}\right]\right)$ of the elementary processes obtained for the microcrystalline $\mathrm{Fe}-x \mathrm{Si}(x=3,5,6.5$, and $7.2 \mathrm{wt} \%)$ ribbons after annealing at $1370 \mathrm{~K}$ for $1 \mathrm{~h}$.

\begin{tabular}{c|c|c|c|c|c|c|c|c|c|c}
\hline \multirow{2}{*}{ Sample } & \multicolumn{2}{|c|}{ Peak I } & \multicolumn{2}{|c|}{ Peak II } & \multicolumn{2}{c|}{ Peak III } & \multicolumn{2}{|c|}{ Peak IV } & \multicolumn{2}{c}{ Peak V } \\
\cline { 2 - 11 } & Q & $A$ & $Q$ & $A$ & $Q$ & $A$ & $Q$ & $A$ & $Q$ & $A$ \\
\hline $\mathrm{Fe}-3 \% \mathrm{Si}$ & 0.84 & 8.6 & 0.90 & 4.2 & 0.98 & 1.9 & 1.07 & 2.1 & 1.18 & 0.8 \\
$\mathrm{Fe}-5 \% \mathrm{Si}$ & 0.84 & 6.4 & 0.91 & 9.4 & 0.99 & 10.4 & 1.05 & 13.2 & 1.12 & 6.1 \\
$\mathrm{Fe}-6.5 \% \mathrm{Si}$ & 0.85 & 4.9 & 0.92 & 8.6 & 0.97 & 16.0 & 1.03 & 13.9 & 1.11 & 8.0 \\
$\mathrm{Fe}-7.2 \% \mathrm{Si}$ & 0.84 & 3.8 & 0.88 & 6.8 & 0.94 & 17.1 & 1.03 & 20.5 & 1.08 & 12.6
\end{tabular}

From analysis of the Mössbauer spectra it was found that the probabilities (equal to the relative areas of the corresponding sextets) for iron atoms to have $8,7,6,5$, and $4 \mathrm{Fe}$ atoms as the nearest neighbours (nn) depend on the silicon concentration (Fig. 8 and Table IV). The probability of the occurrence of 8 and 7 $\mathrm{Fe}$ atoms as nearest neighbours of ${ }^{57} \mathrm{Fe}$ nuclei decreases and 6,5 and 4 increases with increasing Si content in the samples (Fig. 8).

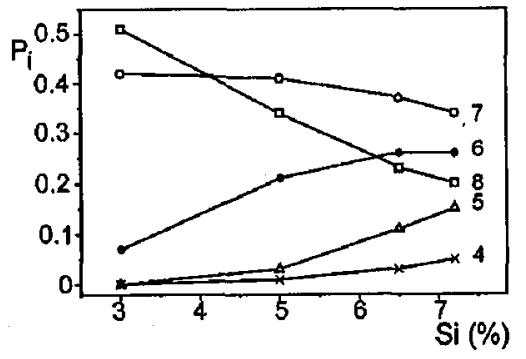

Fig. 8. The probability of the occurrence of $8,7,6,5$, and 4 Fe atoms as nearest neighbours of ${ }^{57} \mathrm{Fe}$ nuclei (curves $8,7,6,5$, and 4 , respectively). 
TABLE IV

The probabilities for iron atom to have $8,7,6,5,4$ iron atoms as nearest neighbours $\left(P_{8}, P_{7}, P_{6}, P_{5}, P_{4}\right)$ obtained for binomial distribution (Bin) and data from the Mössbauer spectra analysis for the microcrystalline $\mathrm{Fe}-x \mathrm{Si}(x=3,5,6.5$, and $7.2 \mathrm{wt} \%)$ samples in the as-quenched state (As-q) and after annealing at $1370 \mathrm{~K}$ for $1 \mathrm{~h}$ (Ann), long and short range order parameters $\left(S_{1}\right.$ for $\mathrm{DO}_{3}, S_{2}$ for $B 2$ and $\alpha_{s}$ obtained from Eqs. (3)-(5)) and the second line intensity in the Zeeman sextets $\left(A_{2,5}\right)$.

\begin{tabular}{|c|c|c|c|c|c|c|c|c|c|c|c|c|}
\hline & \multicolumn{3}{|c|}{$\mathrm{Fe}-3 \% \mathrm{Si}$} & \multicolumn{3}{|c|}{$\mathrm{Fe}-5 \% \mathrm{Si}$} & \multicolumn{3}{|c|}{$\mathrm{Fe}-6.5 \% \mathrm{Si}$} & \multicolumn{3}{|c|}{$\mathrm{Fe}-7.2 \% \mathrm{Si}$} \\
\hline & Bin & As-q & Ann & $\mathrm{Bin}$ & As-q & Ann & $\mathrm{Bin}$ & As-q & Ann & $\operatorname{Bin}$ & As-q & Ann \\
\hline$P_{8}$ & 0.58 & 0.52 & 0.51 & 0.45 & 0.37 & 0.34 & 0.36 & 0.28 & 0.23 & 0.32 & 0.21 & 0.20 \\
\hline$P_{7}$ & 0.33 & 0.42 & 0.42 & 0.38 & 0.42 & 0.41 & 0.39 & 0.37 & 0.37 & 0.39 & 0.36 & 0.34 \\
\hline$P_{6}$ & 0.08 & 0.06 & 0.07 & 0.14 & 0.19 & 0.21 & 0.19 & 0.26 & 0.26 & 0.21 & 0.28 & 0.26 \\
\hline$P_{5}$ & 0.01 & & & 0.03 & 0.02 & 0.03 & 0.05 & 0.08 & 0.11 & 0.07 & 0.14 & 0.15 \\
\hline$P_{4}$ & & & & & & 0.01 & 0.01 & 0.01 & 0.03 & 0.01 & 0.03 & 0.05 \\
\hline$A_{2,5}$ & & 2.3 & 2.8 & & $\begin{array}{c}2.1 \\
1.62\end{array}$ & 2.4 & & 2.2 & 2.8 & & 1.8 & 2.5 \\
\hline$S_{1}$ & & $\begin{array}{r}1.29 \\
(\mathrm{Fe}\end{array}$ & $\begin{array}{l}1.06 \\
\mathrm{Si})\end{array}$ & & $\begin{array}{l}\left(\mathrm{Fe}_{15} \mathrm{Si}\right. \\
1.6 \\
\left(\mathrm{Fe}_{7} \mathrm{Si}\right)\end{array}$ & & & & & & & \\
\hline $\begin{array}{c}S_{2} \\
\alpha\end{array}$ & & 0.27 & 0.27 & & 0.38 & -0.4 & & -0.25 & -0.4 & & -0.35 & $\begin{array}{r}0.53 \\
-0.8\end{array}$ \\
\hline
\end{tabular}

One may conclude (from Figs. 7 and 8 ) that a close relation between the configuration of iron atoms in bcc lattice and the intensities of elementary relaxation processes (I, II, III, IV, and V) exists. The increase in the probability for iron atom to have 6,5 , and $4 \mathrm{Fe}$ atoms as $\mathrm{nn}$ corresponds to the increase in the intensity of elementary processes III, IV, and V responsible for the observed magnetic susceptibility disaccommodation. Simultaneously, the decrease in the probability of the occurrence of 8 and $7 \mathrm{Fe}$ atoms as $\mathrm{nn}$ of ${ }^{57} \mathrm{Fe}$ nuclei takes place which corresponds to the decrease in the intensity of the I and II elementary relaxational processes (Table III, Fig. 7). Thus, the relaxation elementary processes III, IV, and V may be connected with jumping of $\mathrm{C}$ atoms in the neighbourhood of $\mathrm{Fe}$ atoms having 6,5 , and $4 \mathrm{Fe}$ atoms (i.e. 2, 3, and $4 \mathrm{Si}$ atoms) as nearest neighbours. However, the elementary process II (Fig. 7, Table III) may be caused by migration of C atoms in the vicinity of $\mathrm{Fe}$ atoms having $7 \mathrm{Fe}$ atoms (i.e. one $\mathrm{Si}$ atom) as nearest neighbours.

It is worth noting that silicon atoms are not randomly distributed in $\alpha$-Fe-Si lattice because the results obtained from the Mössbauer spectra analysis (Table IV) differ from those obtained for binomial distribution. The Mössbauer spectrum for $\mathrm{Fe}-3 \% \mathrm{Si}$ is decomposed into three Zeeman sextets corresponding to ${ }^{57} \mathrm{Fe}$ atoms having 8,7 , and $6 \mathrm{Fe}$ atoms as nearest neighbours. The ratios of intensities of these Zeeman sextets indicate that $B 2$ and $\mathrm{Fe}_{15} \mathrm{Si}$ superstructure occurs in both as-quenched and annealed samples with $S_{1}$ and $S_{2}$ order parameters listed in Table IV. Similar results are obtained for the as-quenched $\mathrm{Fe}-5 \% \mathrm{Si}$ sample where 
$B 2$ and $\mathrm{Fe}_{15} \mathrm{Si}$ and $\mathrm{Fe}_{7} \mathrm{Si}$ types of superstructure appear. Annealing that sample at $1370 \mathrm{~K}$ for $1 \mathrm{~h}$ and subsequent fast cooling to room temperature changes the long range order into short range order with the parameter $\alpha=-0.4$. For the $\mathrm{Fe}-6.5 \% \mathrm{Si}$ and $\mathrm{Fe}-7.2 \% \mathrm{Si}$ alloy the parameter of the short range order increases after annealing the samples. Additionally, $B 2$ superstructure appears after the annealing of the $\mathrm{Fe}-7.2 \% \mathrm{Si}$ samples.

From the Mössbauer spectra analysis it was also found (Table IV) that the magnetization vector in the as-quenched samples is almost randomly distributed. This is caused by the internal stresses that originate from defects introduced during the ribbon preparation. These internal stresses act as pinning centres for domain walls and strongly influence the magnetic properties in the as-quenched state, i.e. involve the low value of the initial susceptibility (the inset in Fig. 1). These structural defects influence also the intensity of the magnetic susceptibility disaccommodation (the inset in Fig. 3) because some of relaxators are blocked in the strain field of defects [23]. The magnetization vector in annealed ribbons exhibits a tendency to align parallel to the sample surface (Table IV) because of the stress relief of the samples. That relieving leads to the increase in both the magnetic susceptibility and intensity of disaccommodation.

Summing up the results obtained in this paper, the MSD band in microcrystalline $\mathrm{Fe}-x \mathrm{Si}(x=3,5,6.5$, and $7.2 \mathrm{wt} \%)$ ribbons originates from five elementary processes: the carbon Snoek relaxation (directional ordering of single carbon atoms in octahedral sites surrounded by $\mathrm{Fe}$ atoms) and relaxations originating from jumps of $\mathrm{C}$ atoms in the vicinity of $\mathrm{Fe}$ atoms surrounded by 7,6, 5, and $4 \mathrm{Fe}$ atoms (i.e. one, two, three, and four $\mathrm{Si}$ atoms).

It is worth noting that the annealing of the $\mathrm{Fe}-x \mathrm{Si}(x=3,5,6.5$, and $7.2 \mathrm{wt} \%$ ) samples at $1370 \mathrm{~K}$ for $1 \mathrm{~h}$ not only causes the increase in magnetic susceptibility in comparison with $\chi$ for the as-quenched samples but changes the shape of the $\chi=f(T)$ curves as well. The character of these curves depends on the concentration of $\mathrm{Si}$ atoms: the higher concentration of $\mathrm{Si}$ atoms the greater changes of the $\chi=f(T)$ shape.

\section{Conclusions}

1. Magnetic susceptibility disaccommodation in microcrystalline $\mathrm{Fe}-x \mathrm{Si}$ ( $x=3,5,6.5$, and $7.2 \mathrm{wt} \%$ ) ribbons is mainly connected with migrational processes in $180^{\circ}$ Bloch walls.

2. The isochronal disaccommodation curves may be decomposed into five elementary processes (I-V).

3. The correlation between the microstructure and intensity of the magnetic susceptibility disaccommodation is found. The elementary relaxational processes $\mathrm{I}-\mathrm{V}$ are connected with jumping of $\mathrm{C}$ atoms in neighbourhood of $\mathrm{Fe}$ atoms having 8 iron atoms (the Snoek relaxation - process I), and 7,6,5 and $4 \mathrm{Fe}$ atoms (i.e. $1,2,3$ and $4 \mathrm{Si}$ atoms) as nearest neighbours (processes II-V). 


\section{Acknowledgments}

The paper was financially supported by the Committee for Scientific Research (grant No. 7 T082 022 17).

\section{References}

[1] H. Kronmüller, Nachwirkung in Ferromagnetika, Springer, Berlin 1968.

[2] L. Kozłowski, J.W. Moroń, J. Przybyła, J. Rasek, Acta Phys. Pol. A 40, 445 (1971).

[3] L. Kozłowski, J.W. Moron, J. Rasek, Phys. Status Solidi A 13, 601 (1972).

[4] A. Ferro, G. Montalenti, Ricerca Scientifica 25, 3069 (1955).

[5] H. Fahlenbrach, E. Houdremont, Archiv. Eisenhüttenw. 25, 377 (1954).

[6] M. Markuszewicz, B. Wysłocki, K. Stoiński, Acta Phys. Pol. A 23, 59 (1963).

[7] J.W. Moron, Acta Phys. Pol. A 26, 1117 (1964).

[8] K. Tsushima, M. Asanama, S. Miyahara, J. Phys. Soc. Japan 14, 1233 (1959).

[9] K. Tsushima, J. Phys. Soc. Japan, Suppl. BI 17, 338 (1962).

[10] J. Bosman, P.E. Brommer, G.W. Rathenau, J. Phys. Rad. (France) 20, 241 (1959).

[11] W. Ciurzyńska, J.W. Moroń, B. Wysłocki, Y. Yamashiro, Acta Phys. Pol. A 68, 523. (1985).

[12] W. Ciurzyńska, Y. Yamashiro, J.W. Moron, J. Zbroszczyk, B. Wysłocki, Acta Phys. Pol. A 72, 141 (1987).

[13] W. Ciurzyńska, B. Wysłocki, J.W. Moron', Y. Yamashiro, J. Zbroszczyk, Physica $B$ 146, 416 (1987).

[14] W. Ciurzyńska, B. Wysłocki, J.W. Moroń, Y. Yamashiro, in: Conf. Proc. Soft Magnetic Materials 7, Blackpool 1985, Ed. J.E. Thompson, Wolfson Centre for Magnetics Technology, Cardiff 1985, p. 118.

[15] W. Ciurzyńska, J. Zbroszczyk, J. Olszewski, J. Frąckowiak, K. Narita, J. Magn. Magn. Mater. 133, 351 (1994).

[16] W. Ciurzyńska, J. Zbroszczyk, J. Olszewski, J. Frąckowiak, J. Świerczek, B. Wysłocki, S. Szymura, J. Magn. Magn. Mater. 140-144, 87 (1995).

[17] W. Ciurzyńska, J.W. Moroń, J. Zbroszczyk, B. Wysłocki, S. Szymura, J. Rasek, Y. Yamashiro, Mater. Sci. Forum 119-121, 95 (1993).

[18] W. Ciurzyńska, J. Magn. Magn. Mater. 140-144, 87 (1998).

[19] J. Rasek, Acta Phys. Pol. A 44, 85 (1973).

[20] P.S. Rudman, Acta Metall. 8, 321 (1960).

[21] J.M. Cowley, Phys. Rev. 120, 1648 (1960).

[22] L. Néel, J. Phys. Rad. (France) 13, 249 (1952).

[23] F. Walz, H.J. Blythe, W. Merz, Acta Metall. 31, 145 (1983). 